\title{
Drive discrimination in rats following amygdaloid lesions*
}

\author{
ERNEST D. KEMBLE \\ University of Minnesota, Morris, Minnesota 56267
}

\begin{abstract}
Amygdaloid and control Ss were compared on their ability to utilize hunger- and thirst-related cues to guide positional responses in a T-maze. Amygdaloid Ss performed quite accurately when responding to hunger-related cues, but were deficient when responding to thirst-related cues. This difficulty was mirrored by increased amygdaloid VTE behavior on water-deprivation, but not food-deprivation, trials. It is suggested that the amygdaloid lesions either reduced the effectiveness of the water reward or reduced S's ability to employ thirst-related stimuli to guide positional responses.
\end{abstract}

Recently, McGowan, Hankins, and Garcia (1972) have suggested that portions of the limbic system, including the amygdala, are importantly involved in the association of internal with external cues. The primary data suggesting such an interpretation is the difficulty experienced by amygdala-damaged animals in associating a novel taste cue (e.g., saccharin) with LiCL or X-irradiation-induced illness (McGowan et al, 1972; Kemble \& Nagel, 1973; Rolls \& Rolls, 1973). Other data, however, are also amenable to such an interpretation. Pellegrino and Clapp (1971), for example, found that basolateral amygdaloid lesions disrupt uncued, but not cued, DRL performance. The authors suggest that this deficit may arise from a difficulty in utilizing proprioceptive information to guide operant responses in the uncued condition. The well-documented passive avoidance deficits following amygdaloid damage (e.g., Pellegrino, 1968; Ursin, 1965; Thompson \& Schwartzbaum, 1964) as well as the failure of such animals to adjust running speeds normally to altered magnitude of reward (Kemble \& Beckman, 1970a) or to alter open-field activity in response to food deprivation (Kemble, unpublished) may also be interpreted in a similar way. It should be noted, however, that few of the above studies were designed to test the efficiency of such cue utilization. It therefore seemed of interest to explore further the effects of amygdaloid lesions on an animal's ability to utilize internal cues in guiding its behavior. In the present experiment, amygdala-damaged and control Ss were compared in their ability to use cues accompanying hunger and thirst to guide a positional response to an appropriate goal object.

\section{METHOD}

\section{Subjects and Surgical Procedure}

The Ss were 15 male albino rats (Holtzman Co.), weighing $288-325 \mathrm{~g}$ at the time of surgery. These animals had previously served in an investigation of home-cage food and water

*The author would like to thank Mary Ramsay for her help in collecting the data and Jennifer Nagel for the preparation of the figures and assistance with statistical analyses. Address reprint requests to Ernest Kemble, Division of Social Sciences. University of Minnesota, Morris, Minnesota 56267. consumption under varying ambient temperatures $\left(50^{\circ}-80^{\circ} \mathrm{F}\right)$, but had had no other test experience.

Surgery was conducted under barbiturate anesthesia $(45 \mathrm{mg} / \mathrm{kg})$ supplemented by local application of Xylocaine hydrochloride. Amygdaloid lesions $(\mathrm{N}=7)$ were created stereotaxically by passing $2.0-\mathrm{mA}$ anodal current for $20 \mathrm{sec}$ through the uninsulated tip of a stainless steel insect pin positioned $2.2 \mathrm{~mm}$ posterior to bregma, $4.25 \mathrm{~mm}$ lateral to the midline, and $8.25 \mathrm{~mm}$ ventral to the surface of the cortex (head level). Two Ss (operated control) received identical treatment except for current passage, and the remaining six Ss received scalp incisions only.

At the conclusion of testing, experimental Ss were intracardially perfused with isotonic saline followed by $10 \%$ Formalin solution while deeply anesthetized. The brains were then removed, frozen, sectioned at 24 microns (coronal plane), and stained with cresyl violet for histological examination.

\section{Apparatus}

Testing was conducted in an enclosed single-unit T-maze constructed of $1 / 4$-in. plywood, painted flat black throughout, and covered with clear Plexiglas. The startbox was $8 \times 5 \frac{1}{4}$ in., the stem $47 \times 3 \frac{3}{4}$ in., and each arm $81 / 2 \times 4$ in. Each goalbox was $12 \frac{1}{4} \times 5 \frac{1}{4}$ in., with a $2 \frac{1}{4} \times 4 \frac{1}{4}$ in. alcove containing a $1 \frac{1 / 2}{2}$-in. square reward cup. Retracing was prevented by vertically sliding doors. The left arm was baited with eight $45-\mathrm{mg}$ food tablets, and the right arm, with $1 \mathrm{ml}( \pm 0.1 \mathrm{ml})$ of tap water on all trials.

\section{Procedure}

All Ss werc familiarized with the apparatus for 12 days before testing began. On each familiarization day, Ss were deprived of food and water for $23 \mathrm{~h}$, placed in the apparatus with all doors opened, and allowed to consume both the food (left arm) and water (right arm) in the goalboxes. Each $S$ was then returned to its home cage and $15 \mathrm{~min}$ later given ad lib access to food and water for $30 \mathrm{~min}$. All Ss readily ate and drank in the apparatus by the end of this adaptation period.

Following familiarization trials, Ss received 96 training trials. On a random half of the training days, Ss were food deprived only, and on the remaining trials were water deprived only. The Ss received four training trials per day with an intertrial interval of 30-45 sec. For each trial, the "correct" response was a turn to the arm containing the reward appropriate to S's deprivation state. Both S's choice and vicarious trial and errors (VTEs) were recorded on each trial. Fifteen minutes after each day's testing, Ss were given $30 \mathrm{~min}$ ad lib access to both food and water. The Ss were then deprived of the substance appropriate for the following day's test.

\section{RESULTS}

The results of this experiment are summarized in 


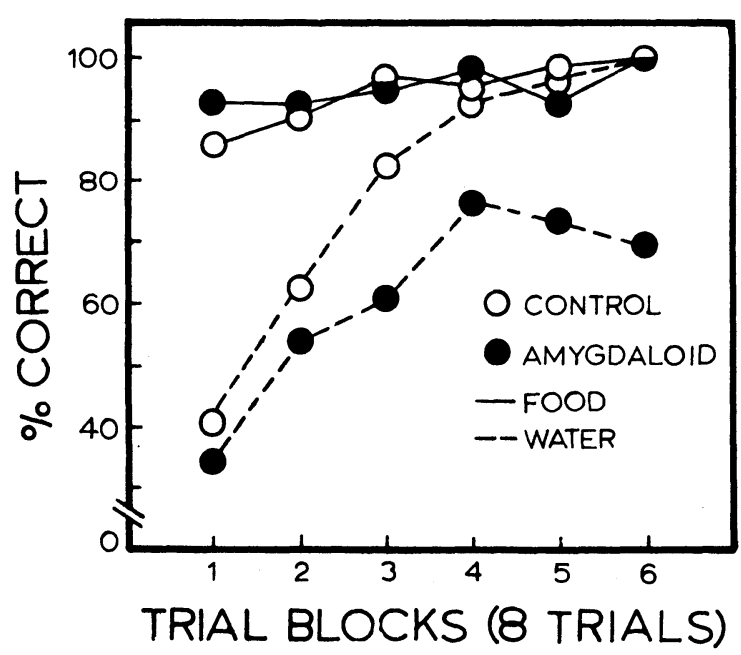

Fig. 1. Percent correct choices by amygdaloid and control Ss on food- and water-deprivation trials.

Fig. 1. It may be seen that appropriate responses on food-deprivation trials were acquired much more quickly than on water-deprivation trials for both control $(p<.02$, sign test) and amygdaloid Ss $(p<.02$, sign test). Analysis of variance revealed that the performance of both amygdaloid and control Ss improved slightly as food-deprivation trials continued $(\mathrm{F}=2.38, \mathrm{df}=11 / 143$, $\mathrm{p}<.05)$ but failed to indicate either group differences $(F<1.0)$ or a Groups by Days interaction $(F<1.0)$. Both groups also improved their accuracy as water-deprivation training continued $(\mathrm{F}=15.02$, $\mathrm{df}=$ $11 / 143, p<.001$ ), but, as can be seen in Fig. 1 , amygdaloid Ss failed to attain the high degree of accuracy achieved by control Ss during the last 24 training trials. This impression is supported by a reliable Groups by Days interaction $(F=2.10, d f=11 / 143$, $\mathrm{p}<.05)$. It is also interesting to note that the relative difficulty experienced by amygdaloid Ss on water-deprivation trials was mirrored in their VTE behavior. Amygdaloid Ss made significantly more VTEs than control Ss on water $(U=8, p<.05)$ but not on food-deprivation trials $(U=15, p<.10)$. This finding confirms an earlier report of increased VTE behavior following amygdaloid lesions (Kemble \& Beckman, 1970b).

At the beginning of this experiment, the body weights of amygdaloid Ss were marginally lower than those of control Ss $(U=13, p<.10)$. This difference was accentuated by the deprivation regimen imposed during training, with control Ss losing 9.5\% of ad lib body weight (range $=6 \%-13 \%$ ) during training as compared to a $13.7 \%$ (range $=8 \%-18 \%$ ) loss by amygdaloid $\mathrm{Ss}(\mathrm{U}=8$, $\mathrm{p}<.05$ ). In neither control nor amygdaloid groups, however, was there any discernible relationship between body weight (or percent weight loss) and performance. Moreover, the two heaviest amygdaloid Ss (who were within the range of control Ss) were distinctly less accurate than control Ss on water-deprivation trials, while the amygdaloid $\mathrm{S}$ who sustained the greatest weight loss (18\%) was excelled by only one control S in accuracy.

Figure 2 presents reconstructions of two representative lesions. These lesions are comparable in size and placement to those reported previously (e.g., Kemble \& Beckman, 1970a, b). Damage was consistently focused about the ventral portions of the amygdaloid complex in the area of the lateral and basal nuclei as well as the adjacent pyriform cortex, while the medial and dorsal portions of the complex were frequently spared. There was no detectable relationship between lesion size or placement and performance.

\section{DISCUSSION}

In view of the greater weight loss by amygdaloid Ss during testing, it might be argued that the poorer performance of amygdaloid Ss on water-deprived trials resulted from increasing drive levels which in some way disrupted performance. However, the failure to find any relationship between weight or weight loss and performance argues against such an interpretation. In addition, we have observed normal ad lib food and water consumption as well as adaptation to food- and water-deprivation schedules in Ss who have sustained similar lesions and whose body weights were reduced relative to control Ss (Kemble, unpublished). Thus, while some more subtle ingestional or regulatory deficit cannot be ruled out, the present data do not appear to reflect a simple alteration in drive level. In view of the similar performance between amygdaloid and control Ss on food-deprivation trials, it is also difficult to see how a general learning deficit could account for the present data.
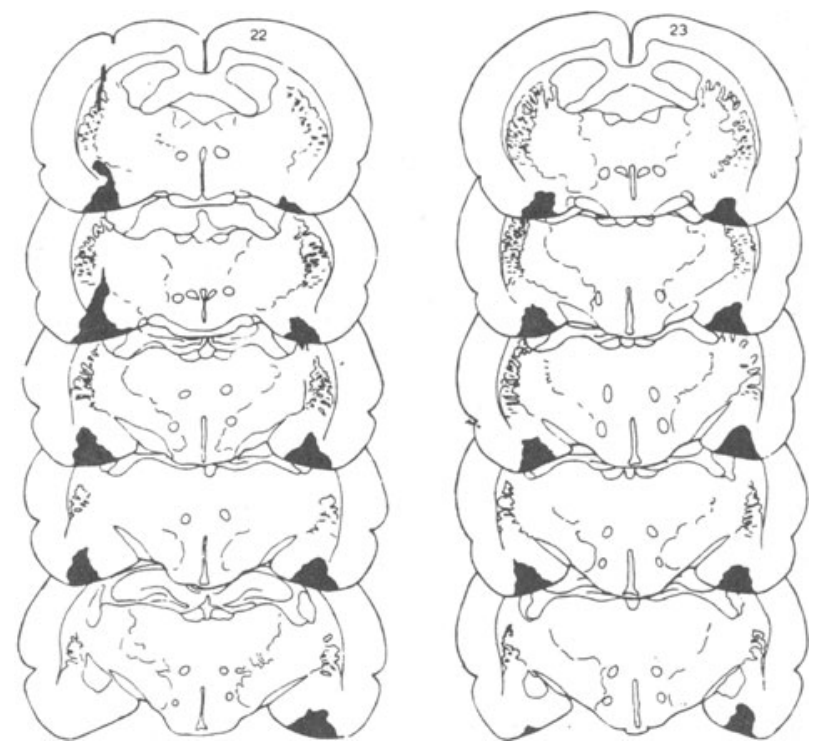

Fig. 2. Tracings of projected coronal sections at 120-micron intervals through the lesions area of a highly deficient $S$ (No. 22) and nonimpaired S (No. 23) on thirst-guided trials. 
The relatively poor performance of amygdaloid Ss during water-deprivation training may have resulted from a reduction in the incentive/motivating properties of the water reward used in this experiment. (It should be noted, however, that amygdaloid Ss rapidly consumed the water reward.) Thus, Kemble and Schwartzbaum (1969) found that amygdaloid damage reduced reactivity to sucrose and quinine solutions. Although no data can be brought directly to bear on this explanation, it should be noted that this deficit may be highly task specific (Rolls \& Rolls, 1973; Kemble, Levine, Gregoire, Koepp, \& Thomas, 1972). Also, the normal adaptation to food and water deprivation noted in our laboratory (Kemble, unpublished) would seem to make this explanation suspect.

The data are also consistent with the view that amygdaloid lesions reduce S's ability to use thirst-related cues in guiding positional responses. Since both control and amygdaloid Ss experienced greater difficulty in utilizing thirst cues, however, it seems safe to assume that hunger and thirst were not equivalent in this experiment. It may well be that amygdaloid Ss would have experienced equivalent difficulty with hunger-guided responses at a different deprivation level. Indeed, passive avoidance deficits have been demonstrated in amygdaloid Ss under both food- (e.g., Thompson \& Schwartzbaum, 1964) and water-deprivation conditions (e.g., McGowan et al, 1972). Also, earlier research (Kemble \& Beckman, 1970b) demonstrated an amygdaloid deficit in a food-rewarded position discrimination in this apparatus. Nevertheless, the possibility that some forms of internal cues may be differentially affected by amygdaloid damage would bear closer examination.
Finally, it is also clear that, under some conditions, amygdaloid Ss utilize hunger-related cues normally in guiding responses. Thus, the forms and/or intensities of internal cues disrupted by amygdaloid damage as well as the test conditions in which deficiencies appear remain to be clarified.

\section{REFERENCES}

Kemble, E. D., \& Beckman, G. J. Runway performance of rats following amygdaloid lesions. Physiology \& Behavior, 1970a, 5, 45-47.

Kemble, E. D., \& Beckman, G. J. Vicarious trial and error following amygdaloid lesions in rats. Neuropsychologia, $1970 \mathrm{~b}, 8,161-169$.

Kemble, E. D., Levine, M. S., Gregoire, K., Koepp, K., \& Thomas, T. T. Reactivity to saccharin and quinine solutions following amygdaloid or septal lesions in rats. Behavioral Biology, 1972, 7, 503-512.

Kemble, E. D., \& Nagel, J. A. Failure to form a learned taste aversion in rats with amygdaloid lesions. Bulletin of the Psychonomic Society, 1973, 2, 155-156.

Kemble, E. D., \& Schwartzbaum, J. S. Reactivity to taste properties of solutions following amygdaloid lesions. Physiology \& Behavior, 1969, 4, 981-985.

McGowan, B. K., Hankins, W. G., \& Garcia, J. Limbic lesions and control of the internal and external environment. Behavioral Biology, 1972, 7, 841-852.

Pellegrino, L. J. Amygdaloid lesions and behavioral inhibition in the rat. Journal of Comparative \& Physiological Psychology, $1968,65,483-491$.

Pellegrino, L. J., \& Clapp, D. F. Limbic lesions and externally cued DRL performance. Physiology \& Behavior, 1971, 7, 863-868.

Rolls, B. J., \& Rolls, E. T. Effects of lesions in the basolateral amygdala on fluid intake in the rat. Journal of Comparative \& Physiological Psychology, 1973, 83, 240-247.

Thompson, J. B., \& Schwartzbaum, J. S. Discrimination behavior and conditioned suppression (CER) following localized lesions in the amygdala and putamen. Psychological Reports, Monograph Supplem ent 4-V15, 1964, 587-606.

Ursin, H. Effect of amygdaloid lesions on avoidance behavior and visual discrimination in cats. Experimental Neurology, $1965,11,298-317$.

(Received for publication February 12, 1974; revision received March 19,1974 .) 